\title{
ISOLATION OF SOME POTENTIAL PHYTOCOMPOUNDS FROM ADHATODA VASICA THROUGH GAS CHROMATOGRAPHY-MASS SPECTROSCOPY ANALYSIS
}

\section{AZIZ MOHAMMAD KHAN, SEEMA BHADAURIA*}

Department of Microbiology, JECRC University, Jaipur, Rajasthan, India. Email: khanazizmohammad@gmail.com

Received: 27 July 2017, Revised and Accepted: 14 September 2017

\section{ABSTRACT}

Objective: The aim of this study is to screen the medicinal compounds present in the leaves, shoots, and flowers of Adhatoda vasica by gas chromatography-mass spectroscopy (GC-MS) analysis.

Methods: Plant leaves, shoots, and flowers were collected, washed, shade dried, and powdered. Methanol extracts of all plant parts were prepared by soxhlation method. All the plant part extracts were analyzed for the identification of phytocompounds present in plant parts using GC-MS and matched by the National Institute of Standards and Technology library.

Results: A wide range of fatty acids and the heterocyclic compound was identified which is responsible for antibacterial, antifungal, anti-inflammatory, and antimycotic activity.

Conclusion: The study concludes that A. vasica have many important important biologically compounds so it can be recommended as a plant of pharmaceutical importance.

Keywords: Adhatoda vasica, Medicinal plant, Screen, Phytocompounds, Gas chromatography-mass spectroscopy.

(C) 2017 The Authors. Published by Innovare Academic Sciences Pvt Ltd. This is an open access article under the CC BY license (http://creativecommons. org/licenses/by/4. 0/) DOI: http://dx.doi.org/10.22159/ajpcr.2017.v10i12.21630

\section{INTRODUCTION}

India is the biggest producer of medicinal plants with the vast geographical area and is also known as the botanical garden of the world. Medicinal plants have several medicinal important compounds such as flavonoids, alkaloids, essential oils, peptides, phenols, and unsaturated long chain fatty acids, which show antibacterial, antifungal, and antiviral activities [1]. These phytochemicals have the important role of protection against diseases. The major advantage of plant-based natural drugs over synthetic drug is that natural drugs are safe, have fewer side effects and are biodegradable. According to the World Health Organization, around $80 \%$ of the world's population use plants for their primary health care [2].

Adhatoda vasica is a highly valued Indian medicinal plant belongs to Acanthaceae family. It is also known as Justicia adhatoda (Linn.), Vasaka and Malabar nut. A. vasica is an erect, terrestrial, and perennial shrub. The leaves are dark green above, and pale yellow below and the flowers are small irregular zygomorphic, bisexual, and hypogynous arranged in a pedunculated spike [3]. The plant leaves, flowers, fruit, and roots are used extensively in the treatment of asthma, cold cough, bronchitis and tuberculosis, joint pain, lumbar pain, sprains, eczema, malaria, rheumatism, swellings, and venereal diseases [4,5].

Plant leaves are anti-inflammatory and effective in skin disorders and cardiotonic [6]. A. vasica also decrease the viscosity of mucous to assist with expectoration and causes thinning of sputum and phlegm and asthma.

In Southeast Asia, various preparations of leaves are used for curing bleeding, hemorrhage, skin diseases, wounds, headache, snake-bites, and leprosy $[7,8]$. The yellow leaves are used for a cough in North India and thus used as an ingredient in cough syrups as an expectorant and antispasmodic [9].
The plant has certain components such as alkaloids, terpenes, triterpenes, phytosterols, flavonoids, essential oils, hydrocarbon, and fatty acids. These components in A. vasica are responsible for antimicrobial, antiasthmatic antitubercular activity, and wound-healing activity.

Gas chromatography-mass spectrometry (GC-MS) is a combination of two different analytical techniques, Gas Chromatography (GC). GC is a technique used to analyze drugs, present in a sample. There are a few reports available in literature on the extraction of phytochemical constitutes in various solvent and analysis of bioactive compound present in A. vasica plant parts using GC-MS. Thus, the present research is aimed to investigate phytochemical analysis and the chemical composition of the selected solvent extract of GC-MS study.

\section{METHODS}

Collection of plant materials

A. vasica plant was collected from Amer, Jaipur district, Rajasthan, and India. The plant was identified by herbarium, University of Rajasthan, Jaipur, and preserved in the laboratory of JECRC University, Jaipur.

\section{Preparation of plant materials}

Plant parts were placed in the laboratory and washed in running tap water to remove dust. Then, plant parts (stems, leaves, and flowers) were cut into pieces, shade-dried in a dust free environment and pulverized to a powder using a grinder separately for extraction. The dry powder was preserved in airtight polythene cover.

\section{Preparation of samples}

The dried powdered samples of plant parts were extracted in Soxhlet extraction unit $[10,11]$. Extraction was done in water and $80 \%$ methanol for $24 \mathrm{hrs}$ on heating mental. The plant extracts are separately filtered using Whatman No. 1 filter paper. The filtrate of methanol extracts was 
then evaporated by heating at water bath at $60^{\circ} \mathrm{C}$. The obtained extracts were stored for GC-MS analysis (Fig. 1).

\section{Interpretation of mass spectrum}

The plant extracts were subjected to GC-MS analysis. For this $1 \mathrm{mg} / \mathrm{ml}$ concentration of the extracted samples is prepared in methanol. The preparation was kept in a sterile glass vial and analyzed for GC-MS.

GC-MS was recorded in a GC-MS-2010 Shimadzu instrument operating in EI mode at $70 \mathrm{ev}$. A Restek-5MS column $(30 \mathrm{~m} \times 0.25 \mathrm{~mm} \times 0.25 \mu \mathrm{m})$ was used. The oven temperature program was $60^{\circ}$ raised to $280^{\circ} \mathrm{C}$ at $5^{\circ} \mathrm{C} / \mathrm{min}$ and held for 2 minutes, then $250-280^{\circ} \mathrm{C}$ at $10^{\circ} \mathrm{C} / \mathrm{min}$ and held for 14 minutes at $280^{\circ} \mathrm{C}$. The injector temperature was $290^{\circ} \mathrm{C}$ with normal injection mode. The flow rate of carrier gas, helium was $1.00 \mathrm{ml} / \mathrm{min}$. A scan interval of 0.5 seconds with a scan range of 41-600 total GC running time was 30 minutes. The identification of compounds was confirmed by comparing the mass spectral data with data obtained from the literature.

\section{RESULTS}

\section{Identification of components}

Identification of phytocompounds was based on the principles of retention time, molecular formula, molecular weight (MW), and concentration (peak area \%). It is done to determine some compounds present in plants having any medicinal value. The GC mass spectrum of the sample was interpreted using the database of National Institute of Standards and Technology (NIST) having more than 2,00,000 patterns. The spectrum of the unknown component was compared with the spectrum of the known components stored in the NIST library. The names of compounds with MW and structure of the test materials were ascertained [12].

\section{A. vasica leaf extract}

Fig. 2 shown in the GC/MS analysis of leaf extracts of $A$. vasica revealed the existence of several compounds. The major compounds identified in A. vasica leaf in terms of area percentage are 9,12,15-octadecatrienoic acid, methyl ester, (Z,Z,Z)- (26.76), 9,12,15-octadecatrienoic acid, (Z,Z,Z)-, linolenic acid (19.44), hexadecanoic acid, methyl ester (16.82), cyclopropaneoctanoic acid, 2-[[2-[(2-ethylcyclopropyl) methyl] cyclopropyl] methyl]-, methyl ester (9.69), methyl (Z)-5,11,14,17eicosatetraenoate(6.03), and binaphthyl sulfone (2.16).

\section{A. vasica shoot extract}

Fig. 3 shown in the major compounds identified in A. vasica shoot in terms of area percentage are 9,12-octadecadienoic acid, methyl ester (39.59), n-hexadecanoic acid (25.86), tricyclo $[20.8 .0 .0(7,16)]$ triacontane, 1(22),7(16)-diepoxy- (10.39), mannitol, 1,3,4,5-tetra-0-methyl-, diacetate, D- (4.64), methanone, [4-(dimethylamino)phenyl]phenyl(3.64), undecane, 6-cyclohexyl- (2.02), linoleic acid trimethylsilyl ester (1.41), and 1-dimethyl(3-chloropropyl) silyloxyoctane (1.46).

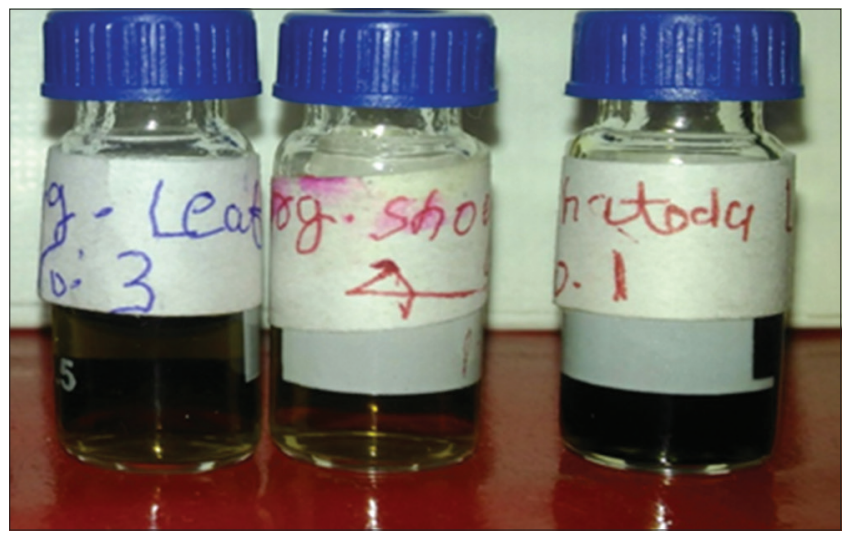

Fig. 1: Samples for gas chromatography-mass spectrometry analysis

\section{A. vasica flower extract}

Fig. 4 show in the similarly, the major compounds identified in A. vasica flower in terms of area percentage are n-hexadecanoic acid (28.47), 9,12-octadecadienoic acid (Z,Z)- (17.68), 9,12,15-octadecatrienoic acid, (Z,Z,Z)- (13.98), octadecanoic acid (11.77), dibutyl phthalate (6.67), hexadecanoic acid, methyl ester (6.53), and 9,12-octadecadienoic acid (Z,Z)-, methyl ester (5.02).

\section{DISCUSSION}

In the phytochemical screening of methanol extract of A. vasica leaves, shoot, and flower powder showed positive results for most of the phytochemical constituents. According to the results, most of the compounds identified, are medicinally very important. For medical practitioners, the role of phytochemical compounds is helpful for the cure of many infections. The most of the compounds identified in this study belong to a fatty acid. Many fatty acids are known to have antibacterial and antifungal properties [13]. Pentadecanoic acid, tetradecanoic acid, hexadecanoic acid, octadecanoic acid, and oleic acids are among the fatty acids known to have potential antibacterial and antifungal activity $[14,15]$. The activity of compounds was identified from Dr. Duke's phytochemical and ethnobotanical database [16] and given in Tables 1-3.

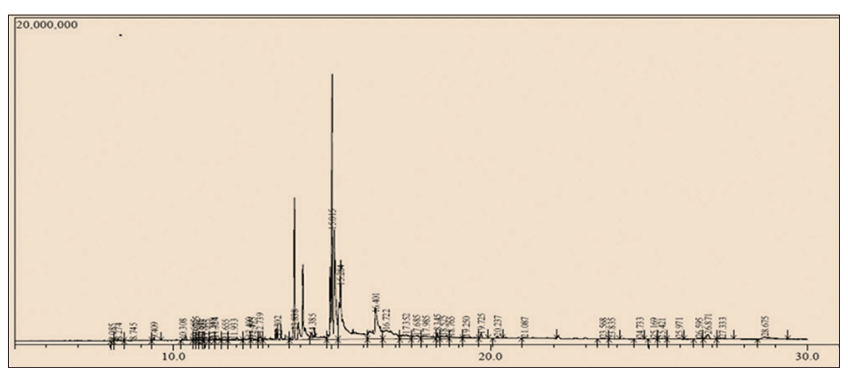

Fig. 2: Gas chromatography-mass spectrometry chromatogram of Adhatoda vasica leaf extract

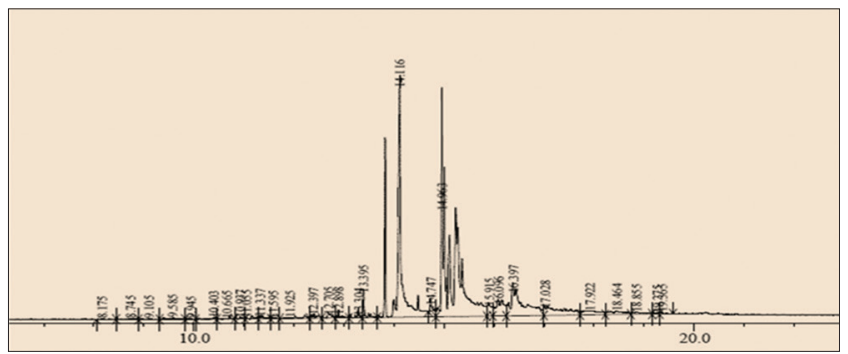

Fig. 3: Gas chromatography-mass spectrometry chromatogram of Adhatoda vasica shoot extract

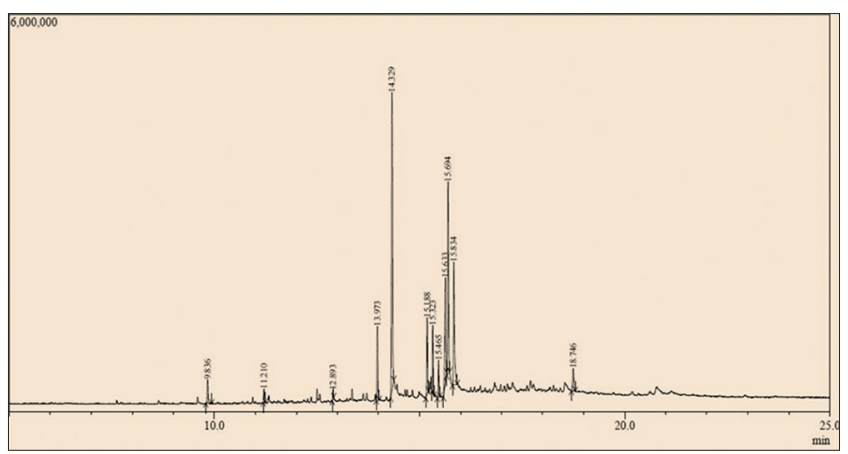

Fig. 4: Gas chromatography-mass spectrometry chromatogram of Adhatoda vasica flower extract 


\section{CONCLUSION}

A. vasica plant and its parts are used for the treatment of asthma, bronchitis, bio-insecticides, and skin diseases. There are few reports on the isolation and identification of bioactive compounds from A. vasica. In this study methanolic extract of $A$. vasica leaf, shoot, and flowers were analyzed for the presence of active bioactive compounds by GC-MS analysis. The major compound identified by GC-MS belongs

Table 1: Phytocomponents identified in the methanol leaf extracts of $\boldsymbol{A}$. vasica

\begin{tabular}{|c|c|c|c|c|}
\hline S. No. & RT & Area & Area \% & Compound name \\
\hline 1. & 11.933 & 1204336 & 0.59 & 2,4-heptadiene, 2,4-dimethyl- \\
\hline 2. & 12.739 & 1413434 & 0.69 & 2-propenoic acid, 3-(4-hydroxyphenyl)-, methyl ester \\
\hline 3. & 13.302 & 5517844 & 2.70 & 2-pentadecanone, 6,10,14-trimethyl- \\
\hline 4. & 13.838 & 34404595 & 16.86 & Hexadecanoic acid, methyl ester \\
\hline 5. & 15.015 & 54755840 & 26.82 & 9,12,15-octadecatrienoic acid, methyl ester, (Z, Z, Z)- \\
\hline 6. & 15.284 & 39767291 & 19.49 & 9,12,15-octadecatrienoic acid, (Z, Z, Z)-, Linolenic acid \\
\hline 7. & 16.401 & 19816699 & 9.69 & Cyclopropaneoctanoic acid, 2-[[2-[(2-ethylcyclopropyl) methyl] cyclopropyl] methyl]-, methyl ester \\
\hline 9. & 17.352 & 4428361 & 2.16 & Binaphthyl sulfone \\
\hline 10. & 17.685 & 2913202 & 1.42 & 5,5-dimethyl-1,3-dioxane-2-ethanol, tert-butyldimethylsilyl ether \\
\hline 11. & 17.985 & 3525626 & 1.72 & 1,3-cyclohexanedione, 5 -isopropyl \\
\hline 12. & 18.525 & 2155917 & 1.05 & Cis-4,7,10,13,16,19-docosahexaenoic acid, trimethylsilyl ester \\
\hline 13. & 18.765 & 1698100 & 0.83 & Binaphthyl sulfone \\
\hline 14. & 19.250 & 1619081 & 0.79 & Diazoprogesterone \\
\hline 15. & 19.725 & 1079474 & 0.53 & Pyrrolo[2,1-b] quinazolin-9 (1H)-one, 3-[2-(dimethylamino) phenyl]-2,3-dihydro- \\
\hline 16. & 21.087 & 1017568 & 0.50 & Dodecanoic acid, 1,2,3-propanetriyl ester \\
\hline 18. & 26.871 & 1834751 & 0.90 & 2-(6-Chloro-benzo[1,3]dioxol-5-ylmethylsulfanyl)-9H-1,3,4,9-tetraaza-fluorene \\
\hline 19. & 28.675 & 2814052 & 1.38 & Gamma-sitosterol \\
\hline
\end{tabular}

RT: Retention time, A. vasica: Adhatoda vasica

Table 2: Phytocomponents identified in the methanol shoot extracts of $A$. vasica

\begin{tabular}{|c|c|c|c|c|}
\hline S. No. & RT & Area & Area \% & Compound name \\
\hline 1. & 12.397 & 1142521 & 0.50 & Methyl tetradecanoate \\
\hline 2. & 12.705 & 1314765 & 0.57 & Tetradecanoic acid \\
\hline 3. & 12.898 & 1040958 & 0.45 & Benzoic acid, 4-hydroxy-3,5-dimethoxy-, hydrazide \\
\hline 4. & 13.304 & 1174574 & 0.51 & 2-pentadecanone, 6,10,14-trimethyl- \\
\hline 5. & 13.395 & 2811456 & 1.22 & 2-propenoic acid, 3-(4-hydroxy-3-methoxyphenyl)-, methyl ester \\
\hline 6. & 14.116 & 59518139 & 25.86 & n-hexadecanoic acid \\
\hline 7. & 14.747 & 1107599 & 0.68 & Heptadecanoic acid \\
\hline 9. & 15.915 & 3356623 & 1.46 & 1-dimethyl (3-chloropropyl) silyloxyoctane \\
\hline 10. & 16.096 & 8375018 & 3.64 & Methanone, [4-(dimethylamino) phenyl] phenyl- \\
\hline 11. & 16.397 & 23919977 & 10.39 & Tricyclo $[20.8 .0 .0(7,16)]$ triacontane, 1 (22),7 (16)-diepoxy- \\
\hline 12. & 17.028 & 10679999 & 4.64 & Mannitol, 1,3,4,5-tetra-0-methyl-, diacetate, D- \\
\hline 13. & 17.922 & 4643559 & 2.02 & Undecane, 6-cyclohexyl- \\
\hline 14. & 18.464 & 3242496 & 1.41 & Linoleic acid trimethylsilyl ester \\
\hline 15. & 18.855 & 1462856 & 0.80 & 7-hexadecenoic acid, methyl ester, (Z)- \\
\hline 16. & 25.185 & 997590 & 0.43 & Octadecanoic acid, 4-methoxy-, methyl ester \\
\hline 18. & 26.523 & 1446286 & 0.63 & 5-Cholestene-3-ol, 24-methyl- \\
\hline 19. & 28.635 & 2693012 & 1.17 & Gamma-sitosterol \\
\hline
\end{tabular}

RT: Retention time, A. vasica: Adhatoda vasica

Table 3: Phytocomponents identified in the methanol extracts of $A$. vasica flower

\begin{tabular}{|c|c|c|c|c|}
\hline S. No. & RT & Area & Area \% & Compound name \\
\hline 1. & 9.836 & 516043 & 2.21 & Hydroquinone \\
\hline 2. & 11.210 & 271287 & 1.16 & Butylated hydroxytoluene \\
\hline 3. & 12.893 & 163495 & 0.70 & Tetradecanoic acid \\
\hline 4. & 13.973 & 1525337 & 6.53 & Hexadecanoic acid, methyl ester \\
\hline 5. & 14.329 & 6651477 & 28.47 & n-hexadecanoic acid \\
\hline 6. & 15.188 & 1558643 & 6.67 & Dibutyl phthalate \\
\hline 7. & 15.323 & 1173754 & 5.02 & 9,12-octadecadienoic acid (Z, Z)-, methyl ester \\
\hline 9. & 15.633 & 2749691 & 11.77 & Octadecanoic acid \\
\hline 10. & 15.694 & 4130083 & 17.68 & 9,12-octadecadienoic acid (Z, Z)- \\
\hline 11. & 15.834 & 3266777 & 13.98 & 9,12,15-octadecatrienoic acid, (Z, Z, Z)- \\
\hline 12. & 18.746 & 634285 & 2.72 & Bis (2-ethylhexyl) phthalate \\
\hline
\end{tabular}

RT: Retention time, A. vasica: Adhatoda vasica 
Table 4: Major compound identified by GC-MS in $A$. vasica

\begin{tabular}{|c|c|c|c|}
\hline S. No. & Name of compound & GC-MS chromatogram & Structure \\
\hline 1. & Hexadecanoic acid & $\begin{array}{lll} & \\
& \\
0\end{array}$ & \\
\hline 2. & 9,12,15-octadecatrienoic acid, (Z, Z, Z) & 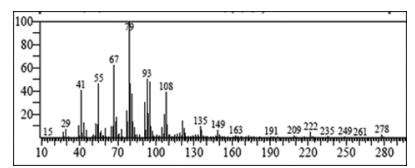 & \\
\hline 3. & $9,12,15$-octadecatrienoic acid & (10) & \\
\hline 4. & Cyclopropaneoctanoic acid & $\underbrace{200}_{10}=0$ & \\
\hline 5. & n-hexadecanoic acid & 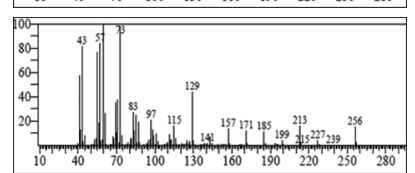 & $c a$ \\
\hline 6. & 9,12-octadecadienoic acid & 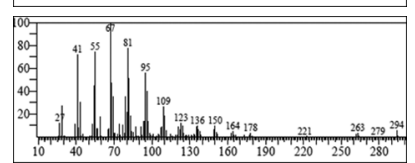 & \\
\hline 7. & Tricyclo[20.8.0.0 $(7,16)]$ triacontane & 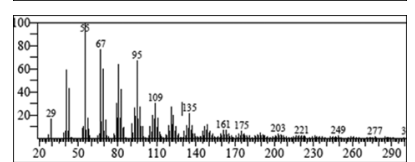 & \\
\hline 9. & 9,12-octadecadienoic acid (Z, Z)- & (1000 & \\
\hline 10. & Octadecanoic acid & (100) & \\
\hline
\end{tabular}

RT: Retention time, A. vasica: Adhatoda vasica, GC-MS: Gas chromatography-mass spectrometry

to fatty acids. These identified phytocompounds are presumed to be responsible for eliciting the traditional activity of $A$. vasica (Table 4).

\section{ACKNOWLEDGMENT}

The authors extend their appreciation to the JECRC University, Jaipur, India, for providing necessary research facilities and support for completion of this work.

\section{REFERENCES}

1. Salna KP, Sreejith K, Uthiralingam M, Prince MA, Milton MC, Fleming AT. A comparative study of phytochemicals investigation of Andrographis paniculata and Murraya koenigii. Int J Pharm Pharm Sci 2011;3(3):291-2.
2. Arunkumar K, Chandrashekar KR. Phytochemical evaluation and in vitro antimicrobial and antioxidant studies of leaf and stem bark extracts of Polyalthia fragrans (Dalz.) bedd.-an endemic species of Western Ghats. Int J Pharm Pharm Sci 2017;9(8):20-4.

3. Shinwari ZK, Shah M. The ethnobotany of Haran district, Balochistan, Pakistan. Proc Sym Med 1995;12:35-8.

4. Chopra RN. Indigenous Drugs of India. Calcutta: Academic Publishers; 1982. p. 264-6.

5. Rastogi RP, Mehrotra BN. Compondium of Indian Medicinal Plants. Vol. 1-5. New Delhi, India: Central Drug Research Institute, Lucknow and National Institute of Science Communication; 1994. p. 188-9.

6. Friesner RA, Murphy RB, Repasky MP, Frye LL, Greenwood JR, Halgren $\mathrm{TA}$, et al. Extra precision glide: docking and scoring incorporating a model of hydrophobic enclosure for protein-ligand complexes. J Med Chem 2006;49(31):6177-96. 
7. Elgal SN, Jasmine R. Identification of the compounds of Adhatoda vasica by gas chromatography-mass spectrometry analysis and probing: The mode of action of the compounds by in silico study. Asian J Pharm Clin Res 2017;10(4):105-8.

8. Adnan M, Hussain J, Shah MT, Ullah F, Shinwari JK, Bahadar A, et al. Proximate and nutrient composition of medicinal plants of humid and Sub-humid regions in Northwest Pakistan. J Med Plant Res 2010;4:339-45.

9. Lal SD, Yadav BK. Folk medicine of Kurukshetra district (Haryana), India. Econ Bot 1983;37:299-305.

10. Subramanian SS, Nagarajan S. Flavonoids of the seeds of Crotalaria retusa and Crotalaria striata. Curr Sci 1969;38:65.

11. Bhadauria S, Kumar P. In vitro antimycotic activity of some medicinal plants against human pathogenic dermatophytes. Indian J Fundam Appl
Life Sci 2011;1(2):1-10

12. Kumaravel S, Kumar PP, Vasuki P. GC-MS study on microbial degradation of lindane. Int J Appl Biochem 2010;6(3):363-6.

13. Russell AD. Mechanisms of bacterial resistance to non-antibiotics: food additives and food and pharmaceutical preservatives. J Appl Bacteriol 1991;71(3):191-201.

14. McGaw LJ, Jäger AK, van Staden J. Isolation of antibacterial fatty acids from Schotia brachypetala. Fitoterapia 2002;73(5):431-3.

15. Seidel V, Taylor PW. In vitro activity of extracts and constituents of Pelagonium against rapidly growing mycobacteria. Int $\mathrm{J}$ Antimicrob Agents 2004;23(6):613-9.

16. Duke JA, Beckstrom-Sternberg SM. Phytochemical and Ethnobotanical Databases, Duke's Phytochemical and Ethnobotanical Databases. Available from: http://huilesutiles.eu/docs/patchouli.pdf. [Last cited on 2013 Mar 11]. 